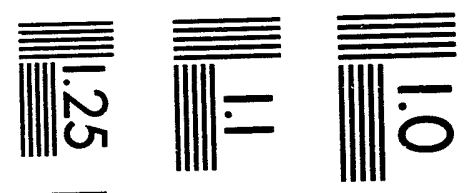

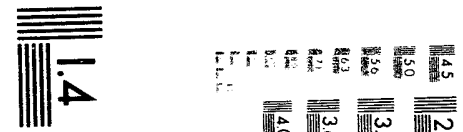

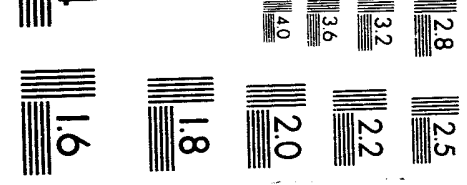



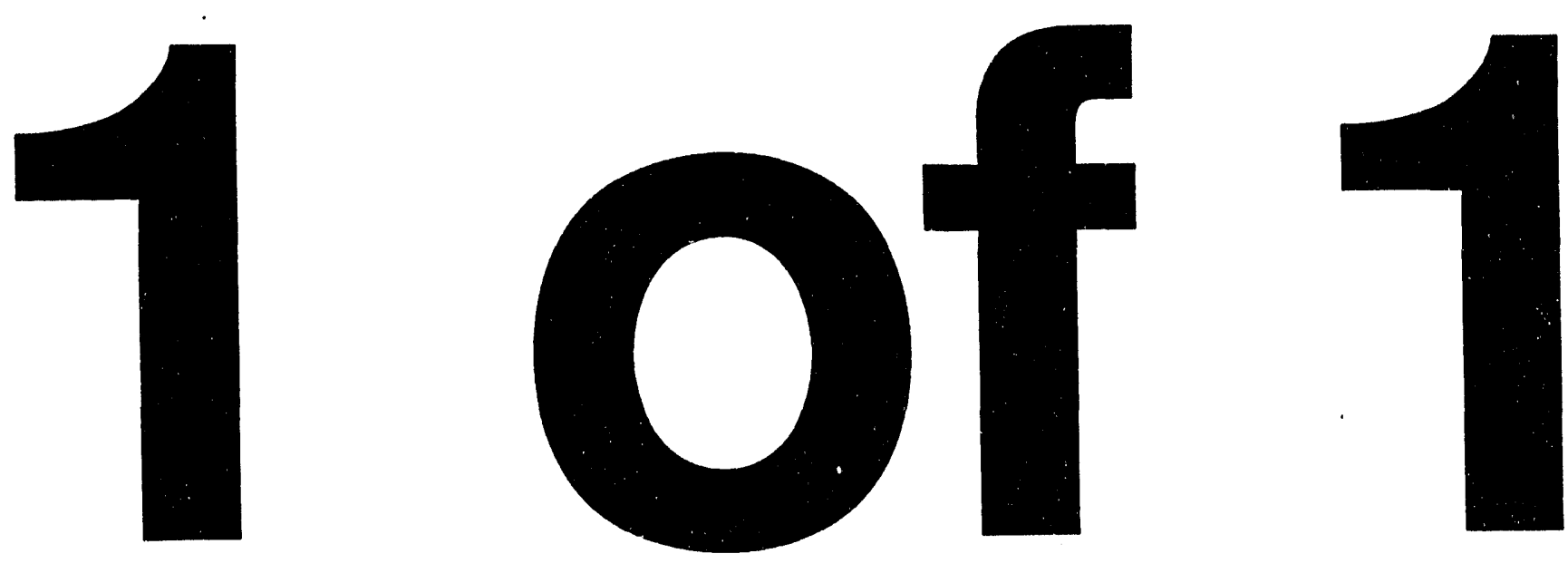
This is a proposal to continue our cooperative program on DIII-D under U.S. Department of Energy contract DE-FG03-89ER51116 ending November 10, 1994. Tasks proposed here are for the period FY94, the final year of the current three-year grant.

Close communication with GA staff members is maintained, as in the past, by computer linkage; by frequent trips to San Diego; and through direct contact with Dr. Gary Porter and other members of the Livermore DIII-D team.

The main objective of the work continues to be providing support for DIII-D data analysis, together with developing and adapting theoretical models as needed. The focus is on divertors, edge physics, and transport phenomena linking edge and core physics.

Since the previous grant proposal was submitted, Dr. Alain Brizard has replaced Dr. Taina Kurki-Suonio as Assistant Research Engineer for the project; and one student, Daniel Hua, completed his Ph.D. work and is now with Dr. Marcel Feix in France.

\section{RECENT PROGRESS}

\section{FLUCTUATIONS AND TRANSPORT FOLLOWING L-H TRANSITION}

The edge turbulence is well documented and from the time evolution of various edge parameters across the L-H transition, it has been concluded that, concomitantly with the observed reduction in the turbulence, there is also a reduction in the anomalous heat transport near the edge. In our previous study on thermal transport in the plasma interior, it was concluded that following an L-H transition, the confinement is improved also in the plasma interior. However, because of the inore severe conditions in the 
plasma core, only recently has it become possible to get spatially resolved fluctuation measurements in the plasma interior. On DIII-D, the far infrared scattering measurements of the density fluctuations are carried out by a GA-UCLA collaboration. As a direct continuation of our earlier work, we have carried out a transport analysis for a series of low-beam-power discharges from the DIII-D tokamak. The focus was to compare thermal transport and turbulent fluctuations in the same discharge for the interior region of thie plasma. A. strong correlation between the suppression in the microturbulence levels and the changes in the (one-fluid) diffusivity were observed: the diffusivity profile peaks in the region where the bulk of the fluctuations is located, and both the diffusivity and the fluctuations show gradual reduction in this region, which should be contrasted to the very abrupt drop in the edge region. Two mechanisms have been suggested for the suppression of microturbulence in the plasma interior: the electric field shear, believed to stabilize turbulence near the edge, has been observed to extend into the plasma core on a lower time scale; and the flattening of the electron density profile in the $\mathrm{H}$-mode plasma core. Unfortunately, the data obtained in this study did not allow for the separation of these two hypotheses. This work was performed by Dr. Taina K. Kurki-Suonio in collaboration with Drs. K. H. Burrell and R.J. Groebner as well as other GA staff members and Dr. C. Rettig from UCLA.

\section{VISCOUS HEATING AND MAIN-ION POLOIDAL ROTATION}

The ion temperature profiles of H-mode DIII-D discharges frequently have quite high edge values. These profiles can also exhibit a region of very weak gradient right inside the steep edge gradient region. Low-beam-power discharges were analyzed for evidence for the so-called viscous heating that could be responsible for the high ion temperatures observed at the edge. Due to the lack of main-ion rotation measurements, the poloidal rotation was deduced from the impurity-ion rotation measurements. This indirect study suggested that the main-ion poloidal rotation could differ significantly from its neoclassical value and, thus, that the viscous heating could be active. Direct main-ion rotation measurements from a later experiment with helium plasma revealed edge rotation speeds well exceeding the standard neoclassical prediction. However, the observed rotation speeds were located in the very edge region where the basic assumption of the standard neoclassical theory is violated (i.e., the observed gradient lengths are not much larger than the poloidal gyroradius). A fluctuation-driven process, which flattens the temperature profile inside the steep- 
gradient region, has subsequently been identified during the $\mathrm{H}$-mode phase. In the VH-mode phase, when the flat spot in the temperature profile disappears, the fluctuation goes away. It is now believed that the transport driven by this fluctuation is the cause of the flat spot, instead of the original viscous heating hypothesis. This work was performed by Dr. Taina K. Kurki-Suonio in collaboration with Dr. K. H. Burrell at GA.

\section{ETG INSTABILITY IN THE SCRAPE-OFF LAYER}

We have extended the conducting-plate instability, as it is applied to the tokamak scrape-off layer (SOL), to divertors with d.c. biasing. Using a set of two-fluid equations, we have investigated the variation of growth rate with bias voltage in the electromagnetic limit. Results have shown that the peak growth rate decreased with increasing bias voltage. This work was performed by Biial Modi, in collaboration with Drs. R. Cohen and X.Q. Xu of LLNL.

\section{ITG STABILITY OF DIII-D PLASMAS}

In the past year, we have completed the modifications of the XU-Rosenbluth ITGstability code, originally developed for circular geometry. The input data now used by the ITG-stability code is composed of the experimental density and temperature profiles as well as the numerically-calculated MHD magnetic geometry of DIII-D plasmas. These equilibrium profiles are retrieved from the DIII-D database by a DIII-D interface code, which enables for the first time a realistic ITG-stability analysis of DIII-D plasma discharges. The new ITG-stability code was then used to: study the ITG-mode stability of a hot-ion H-mode DIII-D plasma discharge (No. 65642); and perform a comparative study of the ITG-mode stability of the L-mode, H-mode, and VH-mode phases of a single DIII-D plasma discharge (No. 75121). These studies were performed by Dr. Alain Brizard with the collaboration of J. Fitzpatrick (a DOE Fusion Technology Fellow), Prof. T. K. Fowler, and Dr. T. K. Kurki-Suonio, Dr. X.Q. Xu (LLNL), Dr. K. H. Burrell and Dr. T.H. Osborne (GA).

\section{DIVERTOR}

Our efforts in the past year have mainly revolved around calibrating the 2-D transport code LEDGE to data from the DIII-D experiment. This will enable us to better 
understand the physics of the plasma edge, and to more confidently predict divertor performance of next-generation tokamaks, such as ITER. More specifically, we have tried to find the best choices for boundary conditions, such as the proper recycling coefficients and whether a fixed wall density is more accurate than a zero-densitygradient condition. We have also studied how varying flux limit parameters in the LEDGE code affected edge and divertor plasma properties. This work was performed by Quang Nguyen (a DOE Fusion Technology Fellow) in collaboration with several staff members at LLNL.

\section{HELIUM ASH REMOVAL}

Helium transport studies were carried out on DIII-D using charge exchange recombination (CER) spectroscopy. Helium transport has been observed by injecting helium gas puffs into a variety of L-mode, $\mathrm{H}$-mode, and $\mathrm{VH}$-mode discharges. Measurements of helium density profiles have allowed us to calculate the diffusion and pinch coefficients for helium transport. The results obtained on DIII-D have compared well with similar experiments on JET, TEXTOR, and JT-60. These studies are important in predicting the helium ash transport properties for ITER and will have important implications for its design. Poor helium transport in reactors could lead to a buildup of fusion ash, causing fuel dilution and possibly quench ignition altogether. An intensive campaign was carried out that examined helium transport behavior in ELMming (Edge Localized Mode) $\mathrm{H}$-mode discharges, and the possibility of using ELMs to eject helium was shown to be valid. This work was pertormed by Daniel F. Finkenthal in collaboration with staff members from ORNL and GA.

\section{SOFT X-RAY ASYMMETRIES}

Dr. Alain Brizard, who replaced Dr. Taina Kurki-Suonio, has continued the collaboration with Dr. Gary Porter at LLNL on the investigation of poloidal asymmetries in the soft $X$-ray emission profiles observed in some DIII-D discharges. This project has recently been put on hold until experimental uncertainties associated with the soft $X$ ray detectors are resolved. 
1. Introduce effects due to sheared EXB and parallel flows into the ITG-stability code (which are presently ignored). The radial electric field, which plays a crucial part in setting up sheared EXB flows, will be determined from experimental measurements on DIII-D and used directly as input data into the ITG-stability code. This step will require modifications to our existing data-retrieving Dill-D interface code. We also plan to update and speed up the ITG-stability code so that it may be used as a fast and reliable tool for data analysis on DIII-D. Once this work is completed, we plan to resume our comparative study of the ITG-mode stability of enhanced-confinement regimes in DIII-D, based on the improved ITG-stability code.

2. Provide assistance to other research groups in incorporating our DIII-D interface code into other existing ITG-stability codes (R.E. Waltz and R.R. Dominguez). We also plan to benchmark the critical gradients obtained from our existing ITG-stability code against the critical gradients obtained by other ITG-stability codes (X. Garbet at Cadarache).

3. Continue our collaboration with LLNL on the application of the conductive-plate instability to biased divertors, by extending the study of two-fluid model in the electrostatic limit. This limit may be more relevant than the electromagnetic limit (previously studied) for the scrape-off regions of current tokamaks. Our plan involves studying the edge-SOL interaction on three fronts: theoretical, numerical (involving simulations in three dimensions), and experimental (involving data analysis). The simulation studies will extend the existing 2-D codes (with limited physics) to include several geometrical and physical effects. We also plan to compare our numerical results with those obtained from data analysis on DIII-D and TEXT.

4. Continue improving the physics models in the LEDGE code in order to better match experimental data. One particular area of emphasis will be developing a more sophisticated flux limit model to better handle non-fluid behavior at the edge. We will also apply the LEDGE code for further modeling of the gaseous divertor concept, to compare with DIII-D experiments. Furthermore, we plan to use improved versions of the LEDGE code to compute the relationship of radial transport and axial heat flow into the divertor on the heat deposition profiles in the divertor. This work will be the basis 
for benchmarking divertor models including the radiation-enhanced gaseous divertor concept of great interest in ITER diverior design, as well as transport models such as the ETG process studied in Task 3, above.

5. Begin applying theories of current profile evolution and disruption control to DIII-D data analysis. This work will build upon experience gained by one graduate student who spent FY93 at MIT working with B. Coppi and others. 


\section{PUBLICATIONS}

A. Journals and Reports (3)

1. I.K. Kurki-Suonie, K.H. Burrell, R.J. Groebner, R. Philipona, and C.L. Rettig,

'Transport and Fluctuations in the Interior of DIII-D Plasmas', Nuclear Fusion 33, 301 (1993).

2. D. Hua, X.Q. Xu, and IK. Fowder, 'Ion Temperature Gradient Modes in Noncircular Tokamak Geometry', Physics of Fluids B4, 3216 (1992); Erratum, Physics of Fluids B5, 1036 (1993).

3. A. Brizard. J.Fitzpatrick. IK. Fowder, X.Q. Xu, K.H. Burrell, and I.K. KurkiSuenie, 'Searching for the ITG Mode in DIII-D', Department of Nuclear Engineering Report No. UC-BFE-038, April 13, 1993.

B. Papers presented at Scientific Meetings (13)

1. A. Brizard. J.Fitzoatrick. T.K. Fowler, X.Q. Xu, K.H. Burrell, and T.H. Osborne, Numerical Investigation of the Ion-Temperature-Gradient Stability of DIII-D Plasmas in Various Modes of Energy Confinement', Presented at the 1993 Sherwood Fusion Theory Conference, Newport, Rhode Island (March 29-31, 1993), Poster 3C31.

2. A. Brizard J.Fitzpatrick. I.K. Fowler, X.Q. Xu, K.H. Burrell, and I.K. KurkiSuenio. 'Searching for the ITG Mode in DIII-D', presented at the U.S.-Japan Workshop on Ion Temperature Gradient Driven Turbulent Transport, Austin, Texas (January 11-14, 1993)

3. R.H. Cohen, X.Q. Xu, and B.C.Modi, 'Parallel-Current Effects and Mode Structure of Endloss-Driven Scrape-Off Layer Instability', presented at the APSDPP Meeting, Seattle, Washington (November 16-20, 1992), Bulletin APS 37 , 1368 (1992). 
4. D. Hua, X.Q. Xu, and IK. Fowler, 'Transport Properties of lon-TemperatureGradient Modes in Non-Circular Tokamak Geometry', presented at the APSDPP Meeting, Seattle, Washington (November 16-20, 1992), Bulletin APS 37 , 1369 (1992).

5. M.R. Wade, D.L. Hillis, J.T. Hogan, DE. Finkenthal, W.P. West, and K.H. Burrell, 'Helium Transport Studies in DIII-D', presented at the APS-DPP Meeting, Seattle, Washington (November 16-20, 1992), Bulletin APS 37, 1411 (1992).

6. R.D. Stambaugh, Q Nquyen, R.J. Groebner, K.H. Burrell, and P. Gohil, 'Edge Ion Orbit Loss and H-mode', presented at the APS-DPP Meeting, Seattle, Washington (November 16-20, 1992), Bulletin APS 37, 1509 (1992).

7. IK. Kurki-Suenio and K.H. Burrell, Investigation of Electron-Ion Temperature Differences at the Edge of H-Mode Plasmas in DIII-D', presented at the APSDPP Meeting, Seattle, Washington (November 16-20, 1992), Bulletin APS 37 , 1510 (1992).

8. DE. Finkenthal D.L. Hillis, M.R. Wade, J.T. Hogan, C.C. Klepper, P.K. Mioduszewski, W.P. West, K.H. Burrell, R.P. Seraydarian, R.J. Groebner, P. Gohil, C.M. Greenfield, and J. Kim, Instrumentation and Calibration of the DIII-D Charge Exchange Recombination Spectroscopy System to Measure Absolute Helium Density Profiles', presented at the APS-DPP Meeting, Seattle, Washington (November 16-20, 1992), Bulletin APS 37, 1568 (1992).

9. R.H. Cohen, S.L. Allen, H.L. Berk, R.B. Campbell, J.A. Crotinger, P.H. Diamond, F.L. Hinton, T.B. Kaiser, D.A. Knoll, J.L. Milovich, N. Mattor, B.C.Modi, W.M. Nevins, A.K. Prinja, G.D. Porter, M.E. Rensink, T.D. Rognlien, M.N. Rosenbluth, D.D. Ryutov, G.M. Staebler, Yu.A. Tsidulkov, and X.Q. Xu, 'Physics and Modelling of Scrape-Off Layer Transport', presented at the 1992 IAEA International Conference on Plasma Physics and Controlled Fusion Research, Wurzburg, Germany (October, 1992).

10. G.M. Staebler, R.E. Waltz, M. Beer, W. Dorland, R.R. Dominguez, C.M. Greenfield, G.W. Hammet, F.L. Hinton, G.D. Kerbel, IK. Kurki-Suonio, and J. 
Wiley, Profile Characteristics of $\mathrm{H}$-mode Bifurcation Models and Turbulence Simulations with Gyro-Landau Fluid Models in Slab and Toroidal Geometry', presented at the 1992 IAEA International Conference on Plasma Physics and Controlled Fusion Research, Wurzburg, Germany (October, 1992).

11. E. Doyle, C. Rettig, K. Burrell, P. Gohil, R. Groebner, I Kurki-Suenie, R. Lahaye, R. Moyer, T. Osborne, W. Peebles, R. Philipona, T. Rhodes, T. Taylor, and J.G. Watkins, 'Turbulence and Transport Reduction Mechanisms in the Edge and Interior of DIII-D H-mode Plasmas', presented at the 1992 IAEA International Conference on Plasma Physics and Controlled Fusion Research. Wurzburg, Germany (October, 1992).

12. D.E. Finkenthal, D.L. Hillis, M.R. Wade, W.P. West, J.T. Hogan, K.H. Burrell, R.P. Seraydarian, R.J. Groebner, P. Gohil, C.C. Klepper, and P.K. Mioduszewski, 'Helium Transport Studies in DIII-D', presented at the 19th Eur. Phys. Soc. Conference, Innsbruck, Austria (1992).

13. D.L. Hillis et al. (D.E.Finkenthal, DIII-D team member), 'Helium Transport in Enhanced Confinement Regimes on the TEXTOR and DIII-D Tokamaks', Presented at the 10th International Conference on Plasma-Surface Interactions in Controlled Fusion Devices, Monterey, California (1992).

\title{
DISCLAIMER
}

\begin{abstract}
This report was prepared as an account of work sponsored by an agency of the United States Government. Neither the United States Government nor any agency thereof, nor any of their employees, makes any warranty, express or implied, or assumes any legal liability or responsibility for the accuracy, completeness, or usefulness of any information, apparatus, product, or process disclosed, or represents that its use would not infringe privately owned rights. Reference herein to any specific commercial product, process, or service by trade name, trademark, manufacturer, or otherwise does not necessarily constitute or imply its endorsement, recommendation, or fivoring by the United States Government or any agency thereof. The views and opinions of authors expressed herein do not necessarily state or reflect those of the United States Government or any agency thereof.
\end{abstract}




\section{ORGANIZATION}

The group is currently operating at the proposed level as follows:

Principal Investigator: T.Kenneth Fowler

Assistant Research Engineer: Alain Brizard

Three (3) Graduate Students

The other graduate students participating in the group are funded by DOE Fusion Technology Fellowship. 


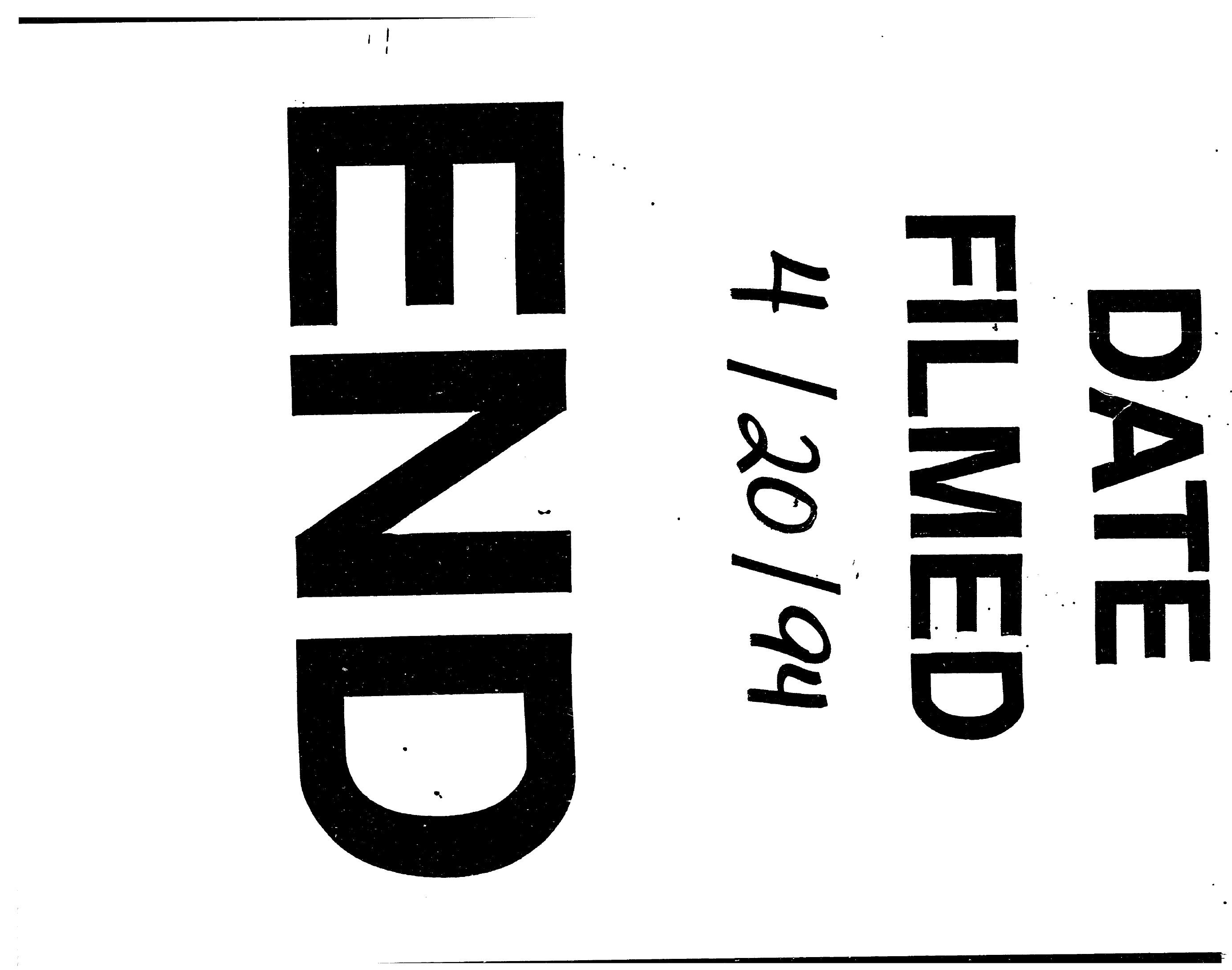

